\title{
REACTION OF HYDROGEN WITH
}

\section{Ag(111): BINDING STATES, MINIMUM ENERGY PATHS AND KINETICS}

Alejandro Montoya, 'Anna Schlunke and Brian S. Haynes

School of Chemical and Biomolecular Engineering, The University of Sydney.

Sydney, NSW 2006, Australia

\footnotetext{
* to whom correspondence should be addressed. email: a.montoya@usyd.edu.au
} 


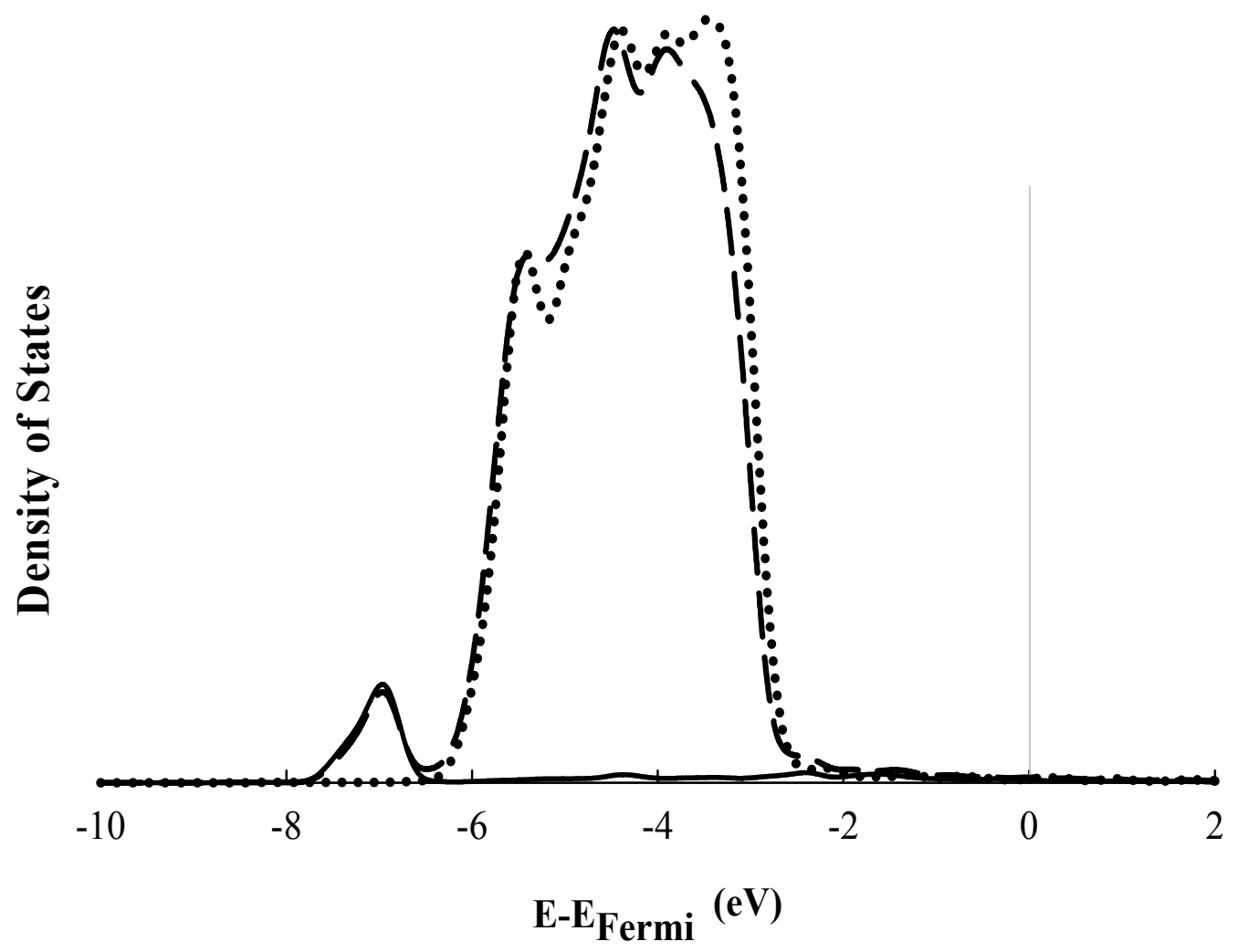

Figure S1. Electronic density of states (DOS) for bare $\operatorname{Ag}(111)$ slab and hydrogen chemisorbed on the fcc site of the $\operatorname{Ag}(111)$ surface at $1 / 4$ ML coverage. Energy is relative to the Fermi energy. Dotted line corresponds to the DOS projected to the $d$ band of the top most layer of the bare slab. Long dashed line corresponds to the DOS projected to the $\mathrm{d}$ band of the top most layer of the $\mathrm{H}$ chemisorbed $\mathrm{Ag}(111)$. Solid line corresponds to the DOS projected to $\mathrm{H} 1 s$ state. 